\title{
DANÇAS POPULARES BRASILEIRAS: TRAJETÓRIAS E EXPERIÊNCIAS CONTRIBUINDO PARA A FORMAÇÃO DOCENTE
}

\author{
POPULAR BRAZILIAN DANCES: TRAJECTORIES AND \\ EXPERIENCES THAT CONTRIBUTE TO TEACHER \\ EDUCATION
}

\section{RESUMO:}

Este artigo objetiva problematizar a trajetória do Projeto 'Danças Populares Brasileiras' mediante as vivências no decorrer das últimas três edições (2015, 2016 e 2017). O Projeto de extensão Danças Populares Brasileiras, criado em 2015, tem como objetivo principal desenvolver danças pertencentes ao repertório nacional das diferentes regiões brasileiras. A imersão nas danças populares brasileiras aproximou as(os) participantes da cultura do Brasil no que tange às danças, pois se fez necessário explorar a diversidade, as influências, os atravessamentos de várias culturas na constituição das danças que hoje ainda existem e são transmitidas de geracão em geração pela oralidade e pelas vivências de determinados grupos. Ao longo das três ediçoes, participaram, aproximadamente, 80 pessoas, entre homens, mulheres e crianças, os quais vivenciaram danças como o Maracatu, Carimbó, Frevo, Forró, Samba de Roda e Samba. Essa ação extensionista propiciou a divulgação, mediante a apresentação em atividades artistico-culturais, bem como em atividades acadêmico-científicas.

Palavras-chave: Educação Física; Danças Populares Brasileiras; Trajetórias; Formação de professores.

\begin{abstract}
:
The present article aims to discuss the development of the Project Popular Brazilian Dances, based on experiences during its last three editions $(2015,2016$ and 2017). The Popular Brazilian Dances Project created in 2015 aims at developing dances belonging to the national repertoire of the different Brazilian regions. The contact with Brazilian popular dances allowed the participants to experience Brazilian culture on a deeper level, in particular dances, as the activities encouraged the exploration of diversity, influences, and the mix of various cultures that constitute the dances. These dances are still part of Brazilian culture and are transmitted from generation to generation orally and through the participation in certain groups. Approximately 80 people participated of the three editions, including men, women and children, who experienced dances like Maracatu,Carimbó, Frevo, Forró, Samba de Roda and Samba. The outreach project action contributed to the dissemination of Brazilian popular dances through their presentation in cultural, artistic, and scientific academic activities.
\end{abstract}

Keywords: Physical Education; Popular Brazilian Dances; Trajectories; Teacher 


\section{Apresentando o Projeto Danças Populares Brasileiras}

O projeto de extensão 'Danças Populares Brasileiras' foi criado em setembro de 2015 , no curso de Educação Física da Universidade Federal do Rio Grande (FURG), configurando-se numa ação extensionista vinculada à formação de professores/as. Assim, os investimentos teóricos visavam ampliar o repertório das danças no que concerne às práticas pedagógicas.

O ponto de partida se deu quando a professora responsável pela disciplina de Danças, no ano de 2012, propôs uma incursão investigativa que se voltou às danças brasileiras na disciplina de Danças do curso de Educação Física, utilizando como recurso didático o documentário 'O povo brasileiro', de Darcy Ribeiro, baseado na obra homônima, para a construção de coreografias que explorassem as matrizes étnicas que miscigenaram o Brasil.

Explorar o universo das danças brasileiras significou uma guinada nos conteúdos, entendidos como relevantes para a formação dos/as professores/as na disciplina de Danças do curso de Educação Física e, para além, produziu concretude à dança, tornando-a mais familiar, humana, histórica e contextualizada. Essa guinada foi alimentada, em certa medida, pelo interesse em "fortalecer identidades culturais nacionais, regionais ou étnicas" ( MONTEIRO, 2011, p.14).

Essa experiência foi o primeiro movimento de aproximação com as danças que compõem o repertório de folguedos e tradições. Culturas, na maioria das vezes, passadas de geração a geração pela oralidade e/ou pelo compartilhamento de comunidades empenhadas em perpetuar suas tradições. Para Monteiro (2011), o alcance cultural que as danças populares possuem se sobrepõe à dança enquanto "belas-artes", pela sua capacidade de penetração na vida cultural e, para ilustrar, cita como exemplos as escolas de samba, afoxés, maracatu e bumba-meu-boi.

Assim, o projeto 'Danças Populares Brasileiras' foi construído partindo-se da necessidade de pesquisa e de escolhas metodológicas para o seu desenvolvimento, pois estava implicado no mesmo uma profunda reflexão acerca das danças elaboradas e vividas na cultura brasileira, mas que não necessariamente ascendem a um patamar artístico.

Em Monteiro (2011), encontramos os subsídios que reafirmam o fazer pedagógico em torno dessa temática, uma vez que a autora investiga a dança enquanto espetáculo de palco, e a dança popular, e analisa-os como dois mundos distintos cercados de polaridades que posicionam, segregam, excluem, atribuindo tempos, espaços e prestígios. Essa distinção tem suas marcas históricas quando se reveste em combate e perseguição. "Do lado da cultura popular, estará muitas vezes o que precisa se combatido, ou cristianizado: as práticas heréticas ou pagãs" (MONTEIRO, 2011, p.31).

A partir desses entendimentos, propôs-se a criação do projeto de extensão 'Danças Populares Brasileiras', que tem como principal objetivo propiciar a vivência de danças oriundas de diferentes regiões brasileiras e que carregam em si contextos, personagens e a historicidade da constituição do povo brasileiro. O Projeto vem sendo submetido, desde então, a editais internos da Universidade, os quais concedem bolsas remuneradas, permitindo, dessa forma, manter a continuidade das atividades propostas.

Assim, consolidou-se o(s) grupo(s), criado(s) com o propósito de desenvolver danças pertencentes ao repertório nacional e que propiciasse uma imersão na cultura das diferentes regiões brasileiras. Para tanto, além das danças, que requerem o compromisso com as construções coreográficas, fez-se necessário explorar o contexto cultural de onde emergem essas expressões artísticas, reconhecendo-se, desse modo, muito mais aproximações na constituição das identidades dos/as brasileiros/as do que afastamentos. As danças que constituem nossas identidades, muitas vezes, esquecidas ao longo do tempo, fazem referência a histórias, a contextos, atores que fazem de seu cotidiano uma festa (CORTÊS, 2000, p.14). Ao final de cada modalidade de dança, foram elaboradas coreografias tendo como horizonte a participação em eventos artístico-culturais, sendo acordado com os/as participantes sobre a disponibilidade e as possíveis intensificações de ensaios para a conclusão das coreografias.

O rol de danças selecionadas para dar início às aulas previa: Samba, Jongo, Carimbó, Maracatu, Frevo, Samba de roda. No momento em que apresentamos a proposta a um grupo composto por 12 mulheres interessadas, que se inscreveram no projeto, fomos interrogadas pelas mesmas sobre a natureza das danças e sua forte relação com danças africanas de cunho religioso. Das 12 mulheres que se inscreveram, apenas uma permaneceu nas aulas, as demais desistiram, pois não queriam participar de danças de cunho religioso ou, como foi manifestado por algumas, "de batuque".

Essa situação, indubitavelmente, potencializou e redirecionou as práticas pedagógicas desenvolvidas ao longo do projeto, uma vez que, além de propor uma imersão em danças desconhecidas pela maioria das participantes, estávamos propondo o diálogo com as contribuições da matriz africana no que concerne à dança, pois são atravessamentos/contribuições imanentes ao dançar do povo brasileiro. O posicionamento e o enfrentamento tornaram-se inevitáveis, uma vez que se fez necessário problematizar por que ainda não reconhecemos as contribuições do povo africano como cultura. Essa situação remeteu-nos à condição do negro (colonizado) e das suas manifestações, aproximando-nos do pensamento de Bhabha, ao afirmar que:

\begin{abstract}
[...] o discurso racista estereotípico, em seu momento colonial, inscreve uma forma de governamentalidade que se baseia em uma cisão produtiva em sua constituicão do saber e exercício do poder. Algumas de suas práticas reconhecem a diferença da raça, cultura e história como sendo elaboradas por saberes estereotípicos, teorias raciais, experiência colonial administrativa e, sobre essa base, institucionaliza uma série de ideologias políticas e culturais que são preconceituosas, discriminatórias, vestigiais, arcaicas, "míticas", e, o que é crucial, reconhecidas como tal. (BHABHA, 1998, p. 127).
\end{abstract}

Em linhas gerais, a situação vivenciada permitiu que lançássemos um olhar mais apurado acerca da cultura brasileira. Os atravessamentos, as aproximações e os afastamentos requereram a inteireza no tratamento das diferenças, da diversidade e da alteridade. Ainda nos encontramos num processo de construção teórico- 
conceitual acerca dos preconceitos, dos estereótipos, mas assumimos, sem dúvida, o posicionamento de enfrentamento e do empoderamento.

Assim, a partir dessas experiências, propomonos a apresentar este trabalho, que tem por objetivo problematizar a trajetória do projeto 'Danças Populares Brasileiras' mediante as vivências no decorrer das últimas três edições (2015, 2016 e 2017).

\section{Caracterizando os grupos ao longo da trajetória}

$\mathrm{O}$ primeiro encontro do Projeto aconteceu em 2015, com a participação inicial de 12 mulheres da comunidade do entorno da Universidade, na faixa etária entre 30 e 50 anos. Contudo, no momento em que o Projeto foi apresentado, houve uma forte resistência dessas participantes ao perceberem se tratar de danças de matriz africana. A partir desse primeiro encontro, das 12 participantes apenas uma permaneceu e, assim, demos início ao Projeto. No decorrer das aulas, outras participantes do entorno da Universidade demonstraram interesse em participar do grupo, totalizando 8 mulheres na faixa etária de 30 a 70 anos. Percebemos, nesse segundo momento, que algumas mulheres apresentavam limitações motoras devido à idade, outras devido a algumas doenças que ocasionaram tal limitação. Essa condição exigiu uma prática pedagógica sensível às limitações na medida em que eram ensinados passos e movimentações característicos dos ritmos apresentados. Ainda assim, o Projeto concluiu sua primeira proposta, a Dança do Carimbó.

No ano de 2016, o Projeto buscou novos horizontes, no sentido de ampliar os conhecimentos acerca das Danças Populares Brasileiras, de forma que alcançasse mais pessoas dispostas a desenvolver e vivenciar nossa cultura através da dança. Isso foi ao encontro do convite realizado por uma assistente social da Unidade Básica de Saúde da Família (UBSF), localizada no bairro São Miguel II (Rio Grande/RS), onde o Projeto passou a ser desenvolvido, permanecendo durante seis meses. $\mathrm{O}$ grupo era composto por 16 mulheres, na faixa etária de 8 a 65 anos. Nesse período, o grupo que desenvolvia o Projeto na Universidade recebeu convites para participar de eventos nos quais foram apresentadas coreografias do Carimbó, do Frevo e do Forró. Os grupos, ao lhes serem solicitados a apresentar seus trabalhos, começaram a mobilizar-se na confecção dos figurinos e adereços. Havia uma preocupação em se apresentarem com os trajes típicos e as pesquisas na internet tornaram-se aliadas na visualização e na produção dos figurinos.

No ano de 2017, o grupo contava, aproximadamente, com 20 participantes mulheres e agora com a presença de homens, do entorno da Universidade, na faixa etária entre 20 e 70 anos, e, concomitantemente, desenvolvia sua atividade em uma nova Unidade Básica de Saúde da Família (UBSF) - Dr. Vicente Mariano Pias localizada no bairro São Miguel I (Rio Grande/RS). Esse grupo era formado por 14 mulheres entre 10 a 60 anos. Nesse ano, o grupo mostrou-se mais consistente e coeso, as/os participantes demonstravam mais entrosamento $\mathrm{e}$ autonomia. Realizavam estudos em casa acerca das indumentárias que determinada dança requeria, além de estarem/sentirem-se mais aproximados das culturas estudadas e vivenciadas.
As apresentações em eventos artístico-culturais geravam um misto de empolgação e ansiedade entre as/os participantes. Após as apresentações, sempre exitosas, sentiam-se com a sensação de dever cumprido, orgulhosas/os da coragem e do enfrentamento ao subirem ao palco e se apresentarem a grandes ou pequenos públicos, situação que, em muitas vezes, ocorria pela primeira vez em suas vidas.

\section{A trajetória do Projeto Danças Populares Brasileiras}

O projeto 'Danças Populares Brasileiras' vem sendo desenvolvido desde 2015, sendo submetido a editais internos da Universidade. $\mathrm{Na}$ última edição (2017), submetemos a proposta no Edital Conjunto de Circulação Interna - PDE/EPEC N $\mathrm{N}^{\circ}$ 01/2017 EPEC/2017, o qual concedeu bolsas através do Subprograma de Formação Ampliada, especificamente na área temática Cultura.

Ao longo dos três anos, o Projeto foi ofertado em duas Unidades Básicas de Saúde da Família (Vera Regina Freitas Theodoro e Dr. Vicente Mariano Pias), ambas localizadas no município do Rio Grande, e na Universidade Federal do Rio Grande (FURG). Foram vivenciadas algumas danças, entre elas: Carimbó, Forró, Frevo, Samba, Maracatu, Samba de Roda e Samba (Puxada de rede).

As danças vivenciadas propõem uma imersão em diferentes contextos culturais. O 'Carimbó', típico da região Norte do Brasil, dançado em roda, é a mistura da criatividade dos índios com os compassos/ritmos dos escravos, possui vestimentas bem coloridas e adereços bem expressivos (CORTÊS, 2000, p. 49).

Já sobre Frevo, Suassuna (2015) relata:

[...] sua origem nos capoeiras que vinham à frente das bandas, exibindo-se e praticando a capoeira, com o objetivo de intimar seus grupos rivais. Surgiu das marchas carnavalescas pernambucanas e dos frutos da evolução das polcas, maxixes e quadrilhas, ganhando novas formas de combinações de passos, acompanhado por músicas animadas e envolventes.

O Maracatu, conhecido como cortejo de negros, era utilizado para acalmar os escravos e manter a ordem. Indumentária rica em adornos, tecidos brilhantes, espelhos e bijuterias para lembrar-se da riqueza deixada na África. O Samba de Roda, originária dos escravos, estende-se por toda a Bahia, é uma dança com muitos giros, dançado com muito requebrado e alegria. E, por último, Puxada de Rede, uma dança originária da Bahia surgiu após o período da escravidão, quando os negros não acharam oportunidades de se encaixar no mercado de trabalho e procuravam seu sustento no mar. E assim, uma parte desses negros se deslocou para as entranhas dos mangues, na região de Santo Amaro (CORTÊS, 2000).

A cultura popular não se resume em um conjunto coerente e homogêneo de atividades. As manifestações da cultura popular se modificam junto com as mudanças da sociedade em que estão inseridas. É parte fundamental dos diversos modos de pensar, sentir, agir de um povo presentes em seu contexto sociocultural historicamente construído (CORTÊS, 2000). 
Assim, de setembro de 2015 até novembro de 2017, o projeto 'Danças Populares Brasileiras' participou de diferentes eventos de cunhos: artísticocultural, acadêmico-científico. Os grupos participaram de diferentes eventos nos municípios do Rio Grande/RS e de São Lourenço do Sul/RS, a saber:

a) $14^{\circ}$ Mostra da Produção Universitária / MPU (2015) - Realizada de 26 a 29 de outubro de 2015, na Universidade Federal do Rio Grande, foi apresentado o trabalho intitulado "Danças Populares Brasileiras" na modalidade comunicação Oral.

b) Rio Grande em Dança (2016) - Realizado nos dias 28 e 29 de abril de 2016, evento promovido em comemoração ao Dia Internacional da Dança, ocorreu nas instalações da Universidade Federal do Rio Grande. Foi apresentada a coreografia pautada no ritmo do Carimbó, configurando-se na experiência mais desafiadora do grupo, pois até então nenhuma das participantes tinham a experiência de dançar para grandes públicos. Ouvimos, após a apresentação, vários relatos da satisfação em participar daquele momento. Convém ressaltar que, até esse momento, o Projeto era desenvolvido somente na Universidade.

c) VII Festival de Práticas Corporais do Curso de Educação Física/I Seminário de Estudos e Pesquisas em Educação Física \& Danças: Diálogos Possíveis (2016) - Realizado nos dias 22, 23 e 24 de junho de 2016, no CIDEC-Sul, na Universidade Federal do Rio Grande. Foram apresentadas coreografias pautadas nos ritmos do Carimbó, do Frevo e do Forró. Na oportunidade, também foi apresentado o trabalho intitulado "Danças Populares Brasileiras: Construindo um caminho", na modalidade pôster.

d) $34^{\circ}$ Seminário de Extensão Universitária da Região Sul/SEURS - Camboriú/SC (2016) - Realizado de 3 a 5 de agosto de 2016, no Campus Camboriú, foi apresentado o trabalho intitulado "TANZ experimentações, estudos e vivências em danças: em foco as Danças Populares Brasileiras", na modalidade comunicação oral.

e) Semana do Idoso (2016) - Realizado no dia 4 de outubro de 2016, evento em comemoração ao dia do Idoso no Shopping Partage em Rio Grande/RS. Foi apresentada a coreografia pautada no ritmo do Maracatu (Grupo da FURG).

f) Encontro Vida Ativa (2016) - Realizado em outubro de 2016, houve o encontro de todos os Grupos 'VIDA ATIVA' do município do Rio Grande/RS. Na oportunidade, foi apresentada a coreografia do Carimbó (Grupo da UBSF) no Campo do Sport Rio Grande Arthur Lawson.

g) $15^{\text {a }}$ Mostra Produção Universitária / MPU (2016) Realizada de 19 a 21 de outubro de 2016, na Universidade Federal do Rio Grande, foram apresentadas as coreografias do Forró (Grupo da UBSF) e do Maracatu (GRUPO da FURG) e, na oportunidade, também foi apresentado o trabalho intitulado "Danças Populares Brasileiras", na modalidade comunicação oral.

h) $3^{\circ}$ Seminário para Mulheres do Campo, das Águas, das Matas (2017) - Realizado de 04 a 06 de maio de 2017 na cidade de São Lourenço do Sul/RS, o grupo da UBSF apresentou as coreografias do Forró e do Carimbó. Na oportunidade, também foi apresentado o trabalho intitulado "Mulheres, saúde e danças populares: diálogos possíveis entre práticas corporais e o empoderamento feminino", na modalidade comunicação oral.

i) VI Extremos do Sul: sustentabilidade e natureza: interfaces com a Educação Física (2017) - Realizado de 15 a 18 de maio de 2017 na Universidade Federal do Rio Grande, com a participação dos dois grupos (UBSF e FURG), com as coreografias Carimbó e Samba de Roda, respectivamente. Também foi apresentado o trabalho intitulado "O Projeto Danças Populares Brasileiras sob a perspectiva da formação inicial", na modalidade comunicação oral.

j) VIII Festival de Artes Corporais do Rio Grande / II Seminário de Estudos e Pesquisas em Educação Física \& Danças: resistências dos corpos (2017) - Realizado nos dias 13 e 14 de julho de 2017 na Universidade Federal do Rio Grande, com a participação dos dois grupos (UBSF e FURG), quando foram apresentadas as coreografias: 'O Mar Serenou', baseada no Samba de Roda, e 'Festa do Interior', baseado no Frevo.

k) V Seminário Interfaces Pedagógicas: licenciaturas em diálogo: "Cidade e escola: Formação, transformação e cidadania" (2017) - Realizado no dia 22 de agosto de 2017, com a participação dos dois grupos (UBSF e FURG), foram apresentadas as coreografias: 'O Mar Serenou', baseada no Samba de Roda, e 'Festa do Interior', baseado no Frevo.

1) $18^{\circ}$ Seminário Institucional do PIBID/FURG: Dez anos de formação acadêmico-profissional (2017) Realizado no dia 23 de novembro de 2017 na Universidade Federal do Rio Grande, foi apresentando com o grupo da FURG a coreografia 'Das raízes... A força de um povo', pautado no Samba.

m) $35^{\circ}$ Seminário de Extensão Universitária da Região Sul / SEURS - Foz do Iguaçu/PR (2017) - Realizado no período de 30,31 de outubro e $1^{\circ}$ de novembro de 2017, foi apresentado o trabalho intitulado "Danças Populares Brasileiras", na modalidade comunicação oral. Ainda no ano de 2017, o grupo da FURG ministrou uma oficina intitulada 'Danças Populares Brasileiras' na $17^{\mathrm{a}}$ Mostra de Produção Universitária (MPU), realizada em outubro, para os inscritos no evento. Essa proposta foi planejada e executada junto com quatro mulheres participantes do grupo. O objetivo foi compartilhar o protagonismo nas atividades desenvolvidas ao longo do Projeto, considerando que sua atuação frente às explicações/orientações das danças permitisse a consolidação da autonomia frente ao grupo, valorizando o pertencimento junto à proposta.

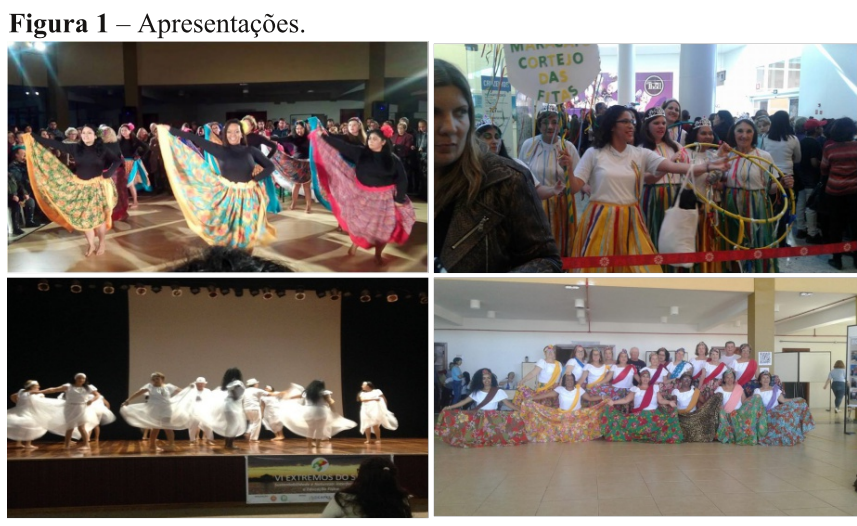

Fonte: Acervo de fotos do Projeto, autorizado e cedido pelos participantes através do Termo de Consentimento Livre e Esclarecido (TCLE). 


\section{Educação Física \& Danças: cenários possíveis}

A primeira ponderação a ser feita acerca da Dança na Educação Física refere-se justamente à ideia de território, de pertencimento. Em documentos oficiais, como os Parâmetros Curriculares Nacionais (PCN) (1997, p.38), o conteúdo 'Dança' é apresentado como 'Atividades rítmicas e expressivas' evidenciando algumas características de seu fazer pedagógico: "a intenção de expressão e comunicação mediante gestos e a presença de estímulos sonoros como referência para o movimento corporal" . Ainda, nesse documento, há indicação de que o trabalho desenvolvido pela/na Educação Física seria complementado pelo documento referente à Dança nos PCN de Arte.

Contudo, encontramos destaque de danças como "o samba, o bumba-meu-boi, o maracatu, o frevo, o afoxé, a catira, o baião, o xote, o xaxado entre muitas outras" (PCN, 1997, p.39) como manifestações potentes da cultura brasileira, evidenciando, nesse sentido, a ausência de um trabalho mais focado nessas manifestações artístico-culturais nas aulas de Educação Física, reforçando ainda a monocultura dos esportes no ensino da área. $\mathrm{O}$ documento segue ainda elencando a diversidade de danças existentes e suas aproximações com o contexto sociocultural, bem como as qualidades de movimentos expressivos que podem ser trabalhadas nas aulas de Educação Física.

Nossa imersão nas danças populares brasileiras ampliou o repertório das práticas curriculares do curso de Educação Física da FURG, na medida em que aproximam os/as acadêmicos/as da cultura do Brasil no que tange às danças, pois se faz necessário explorar a diversidade, as influências, os atravessamentos de várias culturas na constituição das danças que hoje ainda existem e são transmitidas de geração em geração, em grande medida, pela oralidade e pelas vivências de determinados grupos.

\section{Assim, entendemos que:}

Faz-se necessário o resgate da cultura brasileira no mundo da dança através da tematização das origens culturais, sejam do índio, do branco ou do negro, como forma de despertar a identidade social do aluno no projeto de construção da cidadania (COLETIVO de Autores, 1992, p. 82).

$\mathrm{Na}$ obra Metodologia do Ensino da Educação Física (COLETIVO de autores, 1992), elaborada por seis professores/as de Educação Física, imbuídos na ideia de sistematizar os conteúdos da cultura corporal, identificamos um pensamento que renovou o cenário da área para além dos livros de "mil exercícios-atividades". Nesse sentido, a metodologia proposta prevê a ampliação gradual dos conhecimentos como apresentamos, resumidamente, no Quadro 1, a seguir:

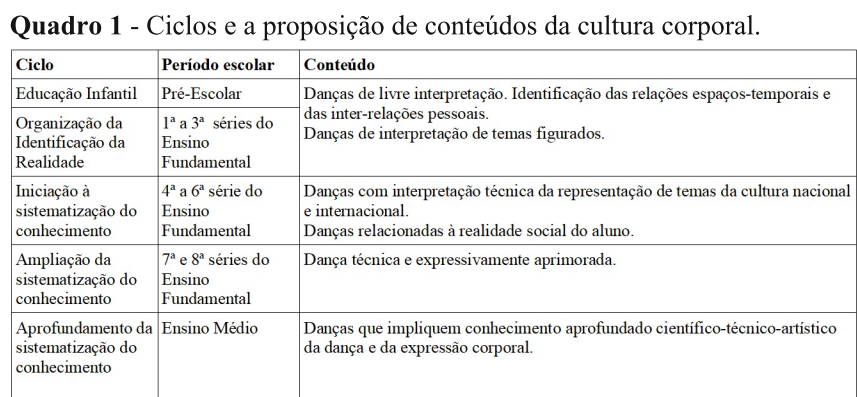

Fonte: Quadro baseado na obra Metodologia do Ensino da Educação Física (COLETIVO de Autores, 1992).

Assumindo essa perspectiva, entendemos a relevância da dança no interior da Educação Física na medida em que "algumas formas de dança utilizam símbolos próprios das culturas a que pertencem, o que as torna de difícil compreensão e interpretação" (COLETIVO de autores, 1992, p.83). Nesse sentido, o empenho encontra-se na capacidade de tornar esse conhecimento acessível e significativo para os sujeitos.

\section{Metodologia do trabalho}

Em todos os contextos em que o Projeto foi desenvolvido, ofertou-se a vivência, duas vezes por semana, com duração de uma hora cada encontro. Esses encontros foram organizados de modo a introduzir, conceitualmente, o contexto histórico e geográfico, características da dança, adereços, figurinos e músicas. A partir dessa contextualização, os grupos passavam a vivenciar os passos típicos de cada dança, a fim de utilizá-los na composição da sequência coreográfica.

Tanto os passos quanto as sequências coreográficas passaram pelo que denominamos de "transposição didática", conceito apresentado Chevallard (2013) e discutido por vários autores/as. Esse conceito adéqua-se ao processo de ensino desenvolvido ao longo dos anos no Projeto, uma vez que, a partir das configurações iniciais de cada dança, percebeu-se que, em alguns casos, fazia-se necessária uma adaptação que permitisse que as movimentações fossem mais palatáveis, assimiláveis por um grupo que, em sua maioria, era composto por senhoras e senhores entre 40 e 76 anos, os quais não possuem mobilidade e/ou agilidade necessárias impressas em algumas danças, como, por exemplo, o frevo.

Nesse sentido, chegar à conformação da sequência coreográfica para a apresentação passou, em cada dança, por processos de adaptação, de mediação didática, como nos diz Lopes (1999), evidenciando, em nosso entendimento, um complexo exercício de formação de professora que, pautada na experiência técnica das danças, buscou, em cada etapa, resignificar, adaptar, mediar a relação das participantes com a dança em sua forma mais técnica, performática.

Ao longo do Projeto, foram desenvolvidas seis sequências coreográficas: Carimbó, Forró, Frevo, Maracatu e Samba de Roda. Em todas essas sequências, o grupo participou na íntegra da produção, pois se envolveram com a criação dos figurinos, da intensificação dos ensaios, da elaboração dos acessórios, bem como dos momentos mais esperados, que foram as apresentações ao grande público. Esses momentos configuraram-se em oportunidades de fortalecimentos dos laços afetivos, pois o grupo mostrava-se coeso e potente no enfrentamento dos desafios de que se revestiam as apresentações públicas.

\section{Entre memórias e trajetórias a potência da ação extensionista para a formação docente}

O projeto 'Danças Populares Brasileiras' vem sendo oferecido, ininterruptamente, desde 2015, através de editais fomentados pela Universidade. Na primeira 
edição, o Projeto foi desenvolvido pelas autoras deste trabalho (bolsista de extensão e coordenadora do projeto). Indiscutivelmente, havia um desafio presente nessa empreitada, uma vez que não havia experiência anterior junto a todas as danças pretendidas. E, para além da apropriação, que se fez necessária de algumas danças que não são pertencentes ao nosso cotidiano na região sul do Brasil, observou-se que a constituição e consolidação do grupo foi uma tarefa permanente.

Nesse sentido, recorremos a diferentes recursos: internet, escolha dos repertórios e das músicas, elaboração de informativos sobre cada dança a ser trabalhada, pois queríamos a imersão nos trajes, nas movimentações, no contexto cultural da produção das determinadas manifestações artísticas. Nosso intuito era de que as(os) bailarinas(os) compreendessem os significados presentes nas movimentações, permitindo, dessa maneira, um envolvimento com a dança de forma íntegra, não como meros repetidores de sequências coreográficas.

A despeito da primeira experiência de negação às linhas de trabalho do Projeto, fez-nos entender e ratificar uma das interfaces da docência. Foi a partir dessa negação que se iniciou a busca de material teórico que pudesse aprimorar os conhecimentos sobre matriz africana, para intensificar as conversas com o grupo, sanar dúvidas e esclarecimentos que poderiam surgir. Esses estudos fizeram reconhecer não só o papel naquele contexto social, como também serviu para consolidar identidades, princípios e discursos destas pesquisadoras, identificando as aproximações e pertencimentos da cultura afro-brasileira.

Outra interface vislumbrada nesse processo foi a constante adequação das movimentações características de cada dança, o que denominamos, anteriormente, de 'transposição didática', conceito que nos pareceu apropriado diante das constantes reformulações e adaptações que foram sendo desenvolvidas. De acordo com esse contexto, fez-se necessário planejar a prática de dança, com o intuito de utilizar figuras mais próximas da sua configuração característica, com atenção aos detalhes e aos movimentos para que as(os) participantes do Projeto pudessem executá-los com êxito. Assim, foram necessárias modificações nos passos, a fim de tornar a vivência possível, mas sem perder a essência do passo, do ritmo. Dessa maneira, o Projeto foi se propondo a dançar com as corporeidades possíveis, com as limitações e potencialidades dos movimentos.

A oferta do Projeto nunca especificou um determinado público. Imaginávamos que, por ser de fácil acesso aos acadêmicos da Universidade, teríamos os mesmos como público. Entretanto, os participantes são, predominantemente, mulheres, muitas moradoras do entorno da Universidade, como também, em um determinado período, o grupo foi constituído por pessoas com limitações físicas diversas (Mal de Parkinson, paralisia cerebral, dificuldades visuais e motoras) para as quais o fator motivador era $o$ sentimento de bem-estar que a dança proporciona, assim como o acolhimento que o Projeto teve em oportunizar essas vivências diferentes do cotidiano das mesmas.

A possibilidade de continuidade que os editais nos permitiram nos últimos anos potencializaram a construção de laços afetivos, relações pessoais que aproximaram as participantes do Projeto. As redes sociais (Facebook, whatsapp) criadas extrapolaram os dois encontros semanais, qualificando as ações extensionistas, pois as decisões são coletivas e assumidas pelo grupo de maneira a apresentarem-se da melhor maneira possível, buscando superar os desafios impostos pelas apresentações artísticas, tais como a produção dos figurinos, a intensificação dos ensaios, a dedicação de tempo para as apresentações, entre outras.

A construção e o desenvolvimento do Projeto vêm oportunizando às acadêmicas envolvida autonomia e segurança para desenvolver as atividades, possibilitando novos horizontes e novos olhares a respeito do ensinar em diferentes perspectivas. Ainda, permitindo ampliar as experiências e propondo uma aproximação com a comunidade, fazendo com que a mesma assuma a responsabilidade de atuar como professora e desenvolver as atividades propostas pela extensão. Essas experiências fortalecem a troca de saberes e conhecimentos, consolidando a formação e contribuindo para sua prática docente.

Para concluir, compreendemos que todo esse processo se reverteu numa experiência formativa que acompanhou as autoras, contemplando a indissociabilidade pesquisa/ensino/extensão, uma vez que todos os espaços formativos foram vivenciados no decorrer deste Projeto.

\section{Referências:}

BHABHA, Homi K. O local da cultura. Belo Horizonte/MG: Editora UFMG, 1998.

BRASIL. Secretaria de Educação Fundamental. Parâmetros curriculares nacionais: Educação Física. Secretaria de Educação Fundamental. Brasília: MEC/SEF, 1997. 96p. Disponível em:

$<$ portal.mec.gov.br/seb/arquivos/pdf/livro07.pdf $>$. Acesso em: 12 mai. 2018.

CHEVALLARD, Yves. Sobre a teoria da transposição didática: algumas considerações introdutórias. Revista de

Educação, Ciência e Matemática, v.3, n.2, mai./ago. 2013.

COLETIVO de autores. Metodologia do ensino de educação física. São Paulo/SP: Cortez, 1992.

CORTÊS, Gustavo Pereira. Dança, Brasil!: Festas e danças populares. Belo Horizonte/MG: Leitura, 2000.

LOPES, Alice Casimiro. Conhecimento escolar: ciência e cotidiano. Rio de Janeiro/RJ: EdUERJ, 1999.

MONTEIRO, Marianna Francisca Martins. Dança popular: espetáculo e devoção. São Paulo/SP: Terceiro Nome, 2011.

SUASSUNA, Ariano. Frevo Patrimônio Imaterial da Humanidade. Disponível em:

$<$ https://www.youtube.com/watch?v=0YoeHJ805iU:>. Acesso em: 04 set. 2015. 